\title{
Metallomesogens as stationary phases for the separation of phenols by gas chromatography
}

\author{
Chuen-Ying Liu*, Cho-Chun Hu, Jien-Lian Chen, Kung-Tien Liu \\ Department of Chemistry, National Taiwan University, Taipei, Taiwan
}

Received 11 June 1998; accepted 24 November 1998

\begin{abstract}
Metal complexes of 4-decanoxydithiobenzoate (DDTBA) and 4-(dec-9'-en-1'-oxy)dithiobenzoate siloxane polymer (PDODTBA) were prepared and used as stationary phases in ligand-exchange gas chromatography for the separation of phenols. A better separation of phenols was achieved in the liquid crystalline state than in the solid state. Van't Hoff plots as a function of temperature indicated that phase transitions were occurring. From specific retention volumes measured at various temperatures in each of the DDTBA-Zn and DDTBA-Ni fluid phases, the thermodynamic behavior of phenols is discussed. The DDTBA-Zn phase showed a higher solute-solvent interaction than DDTBA-Ni. Moreover, DDTBA-Ni phase was more appropriate for the separation of lower volatile phenols. A similar property was exhibited by the metal complexes of PDODTBA. A spiral glass column $(2.1 \mathrm{~m} \times 3.2 \mathrm{~mm}$ i.d. $)$ was prepared from $5 \%$ DDTBA-metal complex deposited on Chromosorb. By dynamic coating, wall-coated P-DODTBA-metal complex capillary columns ( $12 \mathrm{~m} \times 0.25 \mathrm{~mm}$ i.d.) were also prepared as stationary phases for the separation of phenols. Factors affecting the retention and the sample selectivity on both the packed column and the capillary column were examined. The calibration graphs for phenol determination were linear over the range of 64-1600 $\mu \mathrm{g} \mathrm{ml}^{-1}$ (packed column) and 16-400 $\mu \mathrm{g} \mathrm{ml}^{-1}$ (capillary column). The $2 \sigma$ mass detection limits of most phenols are less than $30 \mathrm{ng}$ for packed column and $4 \mathrm{ng}$ for capillary column. (C) 1999 Elsevier Science B.V. All rights reserved.
\end{abstract}

Keywords: Metallomesogens; Metallomesogenic siloxane polymer; Ligand-exchange gas chromatography; Stationary phases; Packed column; Capillary column; Phenols

\section{Introduction}

In recent years, research on liquid crystals has been developing very rapidly both as regards the synthesis of new substances and the knowledge of their properties and applications, as indicated in general monographs and reviews [1] and in those devoted to chromatographic applications [2]. Metallomesogens

*Corresponding author. are metal-containing liquid crystals. The interesting properties derived from the presence of metal atoms in ordered fluid phases have given rise to expectations of new applications of liquid crystals based on metallomesogens. Many metallomesogenic structures have also been introduced into polymeric systems. Metallomesogenic polymers can combine the promising properties of metallomesogens (physical properties of metal entities and molecular ordering of liquid crystals) with the advantageous properties of polymers [3]. In a search of the literature, there are only a few 
reports on the use of metallomesogens for chromatographic applications [4-9].

Among the variety of separation methods, ligandexchange chromatography (LEC) is one of the most powerful techniques for resolving complex-forming substances [10,11]. In a search of new stationary phases with ligand-exchange behavior, the desire to combine the properties of liquid crystals with those of metal complexes has led in our laboratory to the preparation and application of low molecular weight metallomesogens and metallomesogenic polymers $[8,9]$. A new packed column from 4-decanoxydithiobenzoic acid metal complexes [8] and a novel capillary column with wall-coated siloxane polymer of 4-(dec-9'en-1'-oxy)dithiobenzoate metal complexes [9] have been used successfully for the separation of dialkyl sulfides and polycyclic aromatic hydrocarbons.

The determination of phenols is necessary because of their toxicity and their widespread use in industry. Nowadays, the most widely used analytical technique for the determination of phenols is gas chromatography (GC), because of its high sensitivity and resolving power. GC of underivatized phenols using capillary columns with conventional phases is difficult, and in particular nitrophenols tend to tail, even when using highly deactivated columns [12]. To avoid this disadvantage, phenols are derivatized to give less polar compounds with better chromatographic characteristics.

Improved selectivity for the separation of phenols can be achieved using ligand-exchange liquid chromatography. The complexation between phenols and iron(III) coordinated to iminodiacetate chelating resin, Chelex-100, was first demonstrated by Petronio et al. [13]. In later papers, Petronio et al. [14] showed that different substituted phenols could be stripped in succession from the iron-loaded resin by using eluents of increasing $\mathrm{pH}$. In 1984, Petronio et al. further claimed that modified Amberlite CG 4B in the iron(II) form can be used for the quantitative separation of phenolic compounds, a separation that is not possible with the Chelex-iron(II) resin. Shahwan and Jezorek [15] employed iron(III)-loaded 8-quinolinol silica gel as the stationary phase for the separation of phenols by liquid chromatography.

Since metallomesogens are promising as stationary phases for ligand-exchange gas chromatography (LEGC), the aim of this paper is to extend the wider applicability of the dithiolene metal complexes either coated on Chromosorb as a packed column or on the capillary wall for the gas chromatographic separation of phenols which are environmentally important pollutants.

\section{Experimental}

\subsection{Apparatus}

All GC analyses were performed on a Shimadzu (Kyoto, Japan) Model GC-9A gas chromatograph equipped with a flame ionization detector. Both packed column and capillary column systems were examined. A Shimadzu data processor (C-R2A) was used for the determination of retention times. Ammonia-equilibrated nitrogen $(10: 90, \mathrm{v} / \mathrm{v})$ and pure nitrogen were used as the mobile phases.

\subsection{Reagents and chemicals}

Most chemicals were of analytical reagent grade from Merck (Darmstadt, Germany). All liquid reagents and solvents used in moisture-sensitive reactions were distilled and collected over type $4 \AA$ molecular sieves. The solid materials used in moisturesensitive reactions were dried at $110^{\circ} \mathrm{C}$ for $24 \mathrm{~h}$ prior to use. Poly(methylhydrosiloxane) (PS 122, MW= 4500-5000) was purchased from Petrach Systems (Bristol, PA). This reagent was used without further purification.

Twelve representative phenols studied were: 2chlorophenol, phenol, $o$-cresol, $p$-cresol, $m$-cresol, 2,4-dimethylphenol,2,4-dichlorophenol, 2-nitrophenol, 2,4,6-trimethylphenol, 4-bromophenol, 3-methyl-4chlorophenol and 2,4,6-trichlorophenol. These compounds were supplied by Tokyo Chemical Industry (Japan). A stock solution of each compound $(0.2 \mathrm{~g})$ was prepared in ethyl acetate $(25 \mathrm{ml})$ and stored at $4{ }^{\circ} \mathrm{C}$. Working solutions were prepared daily or weekly by diluting these solutions with ethyl acetate.

\subsection{Synthesis of low molecular weight metallomesogens and the metallomesogenic polymer}

The detailed procedures for the preparation of $p$ decanoxydithiobenzoates and their siloxane polymer metal complexes were as already reported $[8,9]$. 


\subsection{Column preparation}

\subsubsection{Packed column}

The $p$-decanoxydithiobenzoate nickel and zinc complexes dissolved in toluene were mixed with Chromosorb W AW-DMCS (80-100 mesh) (5\%, w/ w) and stirred for $1 \mathrm{~h}$ at $60^{\circ} \mathrm{C}$. Excess solvent was removed under reduced pressure. Then the glass column $(2.1 \mathrm{~m} \times 3.2 \mathrm{~mm}$ i.d. $)$ was filled with the metallomesogens deposited on Chromosorb by suction at the column end and under ultrasonic stirring. The packed column was then conditioned for $8 \mathrm{~h}$ at $150^{\circ} \mathrm{C}$.

\subsubsection{Capillary column}

A fused-silica capillary column with an external coating of polyimide ( $\mathrm{J} \& \mathrm{~W}$, Folsom, CA or Ohio Valley Specialty Chemicals, Marietta, $\mathrm{OH}$ ) was chemically coated with the metallomesogenic siloxane polymer as described in the following procedures.

Fused-silica capillaries were first rinsed with methanol and dichloromethane $(5 \mathrm{ml}$ for each) sequentially. Then the capillaries were conditioned at $250^{\circ} \mathrm{C}$ with a gentle flow of nitrogen for about $4 \mathrm{~h}$, and were then ready to be coated using a static procedure. The apparatus for the coating procedure is that proposed by Grob and Grob [16] with some modification. In order to prepare a capillary column ( $12 \mathrm{~m} \times 0.25 \mathrm{~mm}$ i.d.) with film thickness of $0.25 \mu \mathrm{m}$, a solution prepared from $0.020 \mathrm{~g}$ of linear side-chain liquid crystal polymer in $5 \mathrm{ml}$ of dichloromethane (which also contained benzoyl peroxide, the amount being $5 \%(\mathrm{w} / \mathrm{w})$ of the linear polymer) was used to fill the capillary. The column was slowly dipped into a water bath at $40^{\circ} \mathrm{C}$, followed by removal of the solvent under vacuum for $10 \mathrm{~h}$.

For improving the reproducibility and coating efficiency of the procedure, we considered the possibility of coating fused-silica capillaries by the following method. One end of the fused silica sealed with silicone rubber was immersed in ice water. The other end was connected to a buffer capillary column to which a $0.5 \mathrm{~cm}$ diameter empty glass tube was lined up. The latter process was used in order to obtain an almost homogeneous distribution of the deposited material, and as a trap for the vacuum system.

After coating, the columns were placed in the nitrogen-purged oven of a gas chromatograph. The temperature was raised to $200^{\circ} \mathrm{C}$ at $3{ }^{\circ} \mathrm{C} \mathrm{min}^{-1}$. After the heat treatment, the interior column wall formed was purged with nitrogen at $200^{\circ} \mathrm{C}$ for $6 \mathrm{~h}$. During these processes, the cross-linking took place. The column was rinsed with dichloromethane $(5 \mathrm{ml})$ to remove any traces of unreacted material and further purged with nitrogen for about 15 min till a constant stable baseline was obtained.

\section{Results and discussion}

The coordination unsaturation of the central metal ion in nickel- and zinc-4-decanoxydithiobenzoate complexes has been studied in the previous paper [8], and the phase transitions of the nickel-4-decanoxydithiobenzoate complexes (DDTBA-Ni) were: $\mathrm{K}$ 140.2 - SmH 167.5 - SmC 235 - I and those for DDTBA-Zn were: K 131.4 - SmC 160.9 - N 173.2 - I; where $\mathrm{K}$ denotes the solid phase, Sm the smectic phase, $\mathrm{N}$ the nematic phase, and I the isotropic liquid. While the phase transitions of the nickel-4-(dec-9'-en$1^{\prime}$-oxy)dithiobenzoate complex (DODTBA-Ni) were: K 122.6 - SmH 162.9 - SmC 230 - I and those for DODTBA-Zn were K 123.1 - SmC 140.8 - N 162.9 I. For examining the ligand-exchange retention behavior and selectivity of phenols on these stationary phases, several types of phenols with different molecular structures were studied: 2-chlorophenol (b.p. $174^{\circ} \mathrm{C}$; length to breadth $(L / B)$ ratio 1.106$)$, phenol $\left(180^{\circ} \mathrm{C} ; 1.280\right), o$-cresol $\left(191^{\circ} \mathrm{C} ; 1.003\right), p$-cresol $\left(202^{\circ} \mathrm{C} ; 1.625\right), \quad m$-cresol $\left(203^{\circ} \mathrm{C} ; 1.183\right), 2,4-$ dimethylphenol $\left(210^{\circ} \mathrm{C}\right.$; 1.271), 2,4-dichlorophenol $\left(210^{\circ} \mathrm{C} ; 1.265\right), 2$-nitrophenol $\left(214^{\circ} \mathrm{C} ; 1.024\right), 2,4,6-$ trimethylphenol $\left(220^{\circ} \mathrm{C} ; 1.063\right)$, 4-bromophenol $\left(238^{\circ} \mathrm{C}\right.$; 1.458$), 3$-methyl-4-chlorophenol $\left(235^{\circ} \mathrm{C}\right.$; $1.110)$ and 2,4,6-trichlorophenol $\left(246^{\circ} \mathrm{C} ; 1.146\right)$.

\subsection{Optimization of experimental variables}

\subsubsection{Packed column}

The retention times of some typical phenols were measured at various temperatures (Fig. 1). $p$-Cresol and 2,4-dimethylphenol were coeluted at a column temperature of $120^{\circ} \mathrm{C}$. With increasing column temperature, the retention of samples was reduced and the peak shape was improved. Additionally, better resolution between $p$-cresol and 2,4-dimethylphenol was found. However, shorter retention times caused poor 

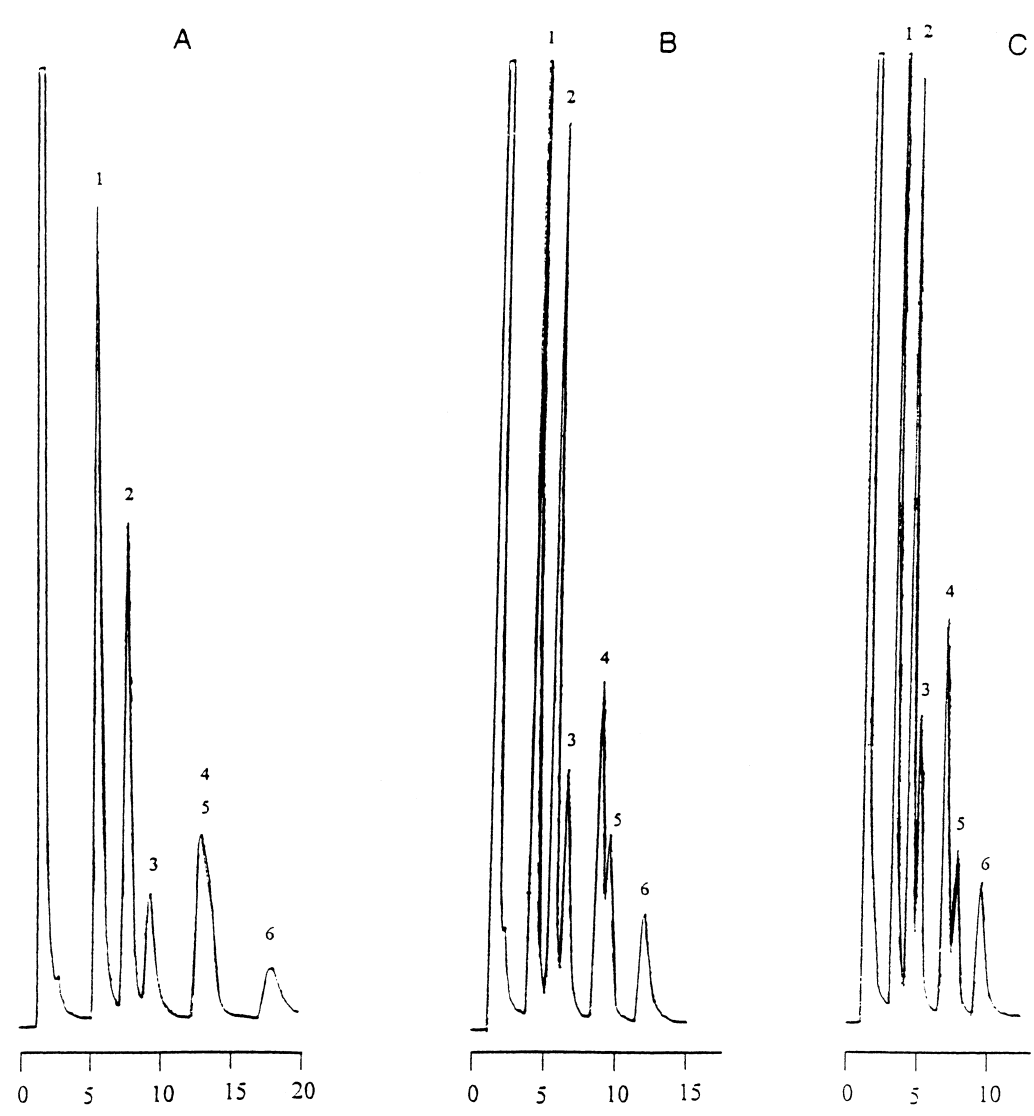

\section{RETENTION TIME (MIN)}

Fig. 1. Chromatogram of the separation of phenols at different temperatures. Stationary phase: 5\% DDTBA-Ni coated on Chromosorb, $2.1 \mathrm{~m} \times 3.2 \mathrm{~mm}$ i.d. glass column; injector temp.: $230^{\circ} \mathrm{C}$; mobile phase: nitrogen gas, flow rate: $40 \mathrm{ml} \mathrm{min}^{-1}$; sample volume: $1 \mu 1$. Oven temp.: (A) $120^{\circ} \mathrm{C}$; (B) $130^{\circ} \mathrm{C}$; (C) $140^{\circ} \mathrm{C}$. Peak identification: (1) phenol; (2) 2-chlorophenol; (3) $o$-cresol; (4) $p$-cresol; (5) 2,4dimethylphenol; (6) 2,4-dichlorophenol.

sample selectivity for 2-chlorophenol and $o$-cresol. Fig. 2 shows the separation of phenols at $145^{\circ} \mathrm{C}$ with both DDTBA-Zn and DDTBA-Ni packed columns. These stationary phases exhibit higher efficiency in the liquid crystal state than in the solid state. The results display a higher column efficiency and better reproducibility for the DDTBA-Ni column in comparison with DDTBA-Zn. Moreover, the utility of DDTBA-Zn in the analysis of high b.p. phenols is diminished by the rather long elution times and the broad bands.

Programmed temperature runs were also carried out with an initial temperature of $140^{\circ} \mathrm{C}$ at $3^{\circ} \mathrm{C} \mathrm{min}^{-1}$ to the final temperature of $165^{\circ} \mathrm{C}$. An improved resolu- tion for 2-chlorophenol and $o$-cresol was obtained (Fig. 3). With extension of the programmed temperature range, more phenols could be separated in a shorter time, but serious baseline drift was observed.

Phase transitions of these stationary phases in GC can be detected from a plot of $\log k^{\prime}$ vs. $1 / T$ (Fig. 4). The capacity factor first decreases gradually with an increase of column temperature from $115^{\circ} \mathrm{C}$, with a discontinuity at around $140^{\circ} \mathrm{C}$, and then decreases markedly. Transition temperatures are clearly indicated by the discontinuities in the curves. The temperature of $140^{\circ} \mathrm{C}$ corresponds to the phase transition point of DDTBA-Ni. Gas-liquid chromatography has become an established technique for the determination 

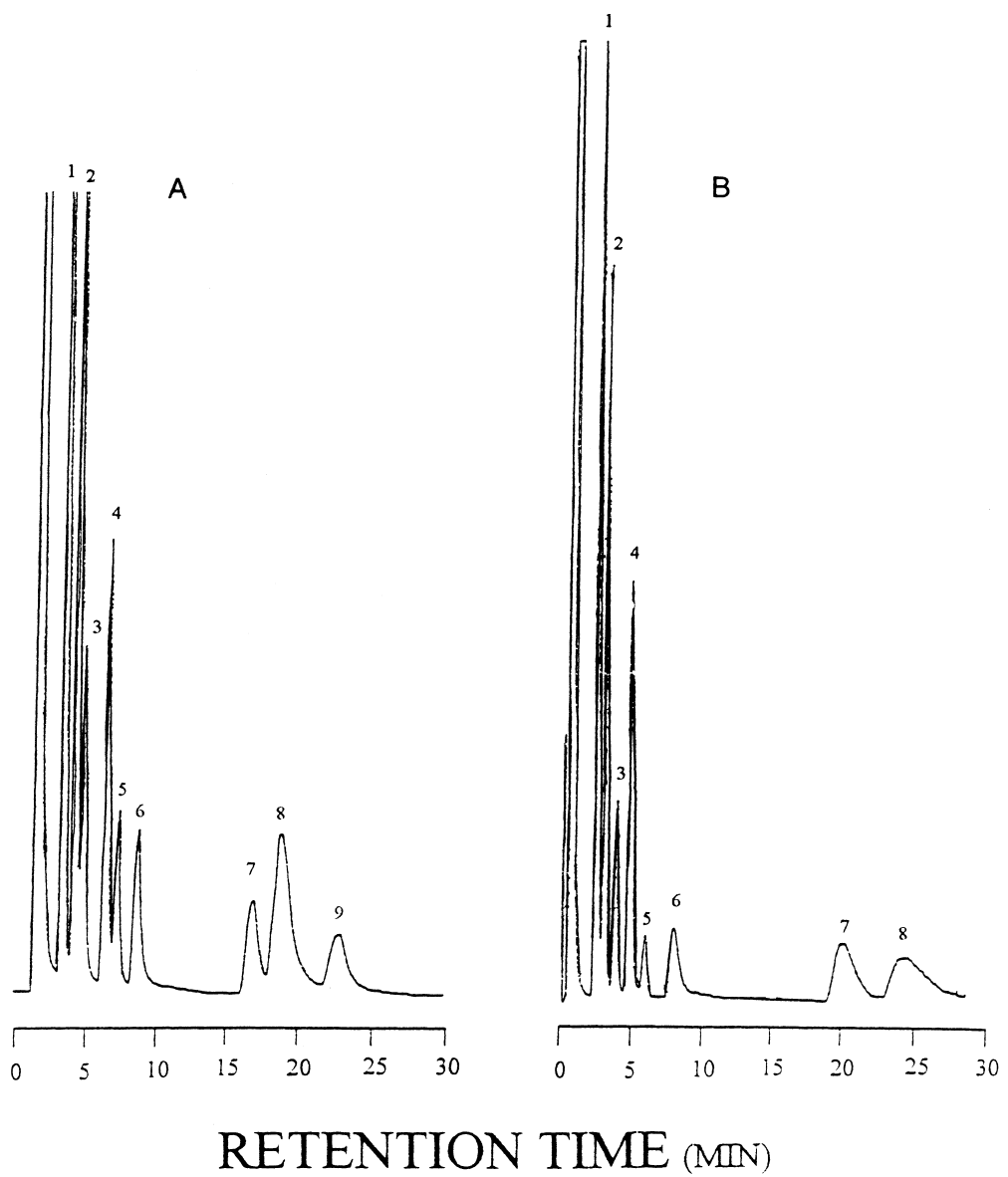

Fig. 2. Chromatogram of the separation of phenols at the liquid crystalline state. Conditions as in Fig. 1 , except column temperature $=145^{\circ} \mathrm{C}$. Stationary phase: (A) 5\% DDTBA-Ni coated on Chromosorb; (B) 5\% DDTBA-Zn coated on Chromosorb. Peak identification: (A) (1)-(6) as Fig. 1; (7) 3-methyl-4-chlorophenol; (8) 4-bromophenol; (9) 2,4,6-tricholorophenol. (B) (1)-(6) as Fig. 1; (7) 3-methyl-4-chlorophenol; (8) 4bromophenol.

of reliable thermodynamic data for volatile solutes at "infinite dilution" in non-volatile solvents [17-19]. Specific retention volumes, $V_{\mathrm{g}}^{\mathrm{o}}$, were obtained at five temperatures in each of the metallomesogenic phases - DDTBA-Ni and DDTBA-Zn. The infinite-dilution solute partial molar enthalpy and entropy of solution were obtained by means of the following equation [20]:

$$
\begin{aligned}
& \ln \left(V_{\mathrm{g}}^{\mathrm{o}}\right)=-\Delta H / R T+\Delta S / R-\ln (M / 273.2 R), \\
& V_{\mathrm{g}}^{\mathrm{o}}=V^{\prime} / W, \quad V^{\prime}=\left(t_{\mathrm{r}}-t_{\mathrm{o}}\right) \times f,
\end{aligned}
$$

where $t_{\mathrm{r}}$ is the retention time of the sample; $t_{\mathrm{o}}$ the retention time of the non-adsorbed substance; $V^{\prime}$ the retention volume; $f$ the flow rate of the carrier gas; $W$ the weight of the stationary phase; $M$ the molecular weight of the stationary phase; and $V_{\mathrm{g}}^{\mathrm{o}}$ is the specific retention volume.

A linear least-squares fit of $\ln V_{\mathrm{g}}^{\mathrm{o}}$ vs. the reciprocal of the absolute temperature (Fig. 5) yields $\Delta H$ and $\Delta S$ as shown in Table 1. By comparing the enthalpy and entropy changes of polycyclic aromatic hydrocarbons (PAHs) [8] with those of phenols, the more effective strength of solute-solvent attractive interactions for phenols was observed, leading to larger $\Delta H$ and $\Delta S$ values. This is not surprising if one takes into account the different complexation ability between PAHs and phenols toward the central metal ion of the metallo- 


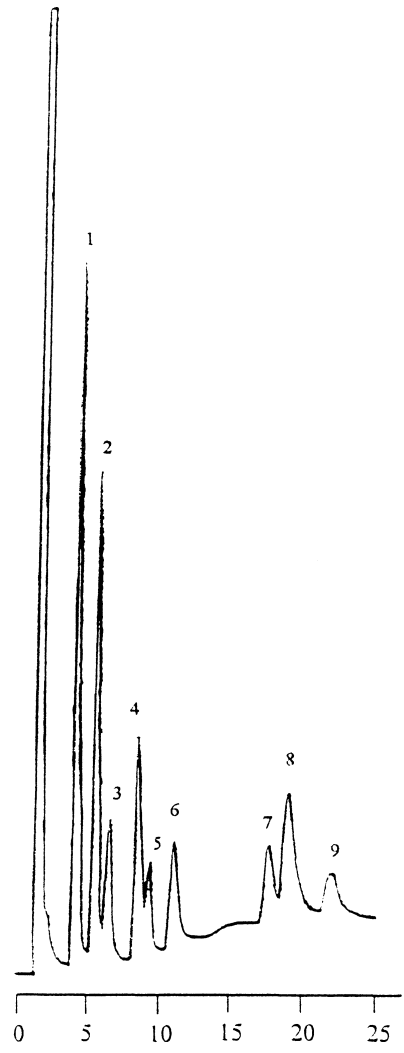

RETENTION TIME (MIN)

Fig. 3. Separation of phenols with programed temperature. Stationary phase: 5\% DDTBA-Ni coated on Chromosorb, $2.1 \mathrm{~m} \times 3.2 \mathrm{~mm}$ i.d. glass column; oven temp.: $140^{\circ} \mathrm{C}$ ( $\left.3 \mathrm{~min}\right)$ to $165^{\circ} \mathrm{C}$ at $3^{\circ} \mathrm{C} \mathrm{min}{ }^{-1}$; injector temp.: $250^{\circ} \mathrm{C}$; mobile phase: nitrogen gas, flow rate: $40 \mathrm{ml} \mathrm{min}^{-1}$. Peak identification: (1) phenol $\left(t_{\mathrm{r}}=4.52 \mathrm{~min}\right)$; (2) 2-chlorophenol $\left(t_{\mathrm{r}}=5.97 \mathrm{~min}\right)$; (3) $o$-cresol $\left(t_{\mathrm{r}}=6.91 \mathrm{~min}\right) ;(4) p$-cresol $\left(t_{\mathrm{r}}=9.01 \mathrm{~min}\right) ;$ (5) 2,4-dimethylphenol $\left(t_{\mathrm{r}}=9.84 \mathrm{~min}\right)$; (6) 2,4-dichlorophenol $\left(t_{\mathrm{r}}=11.53 \mathrm{~min}\right)$; (7) 3methyl-4-chlorophenol ( $\left.t_{\mathrm{r}}=15.87 \mathrm{~min}\right)$; (8) 4-bromophenol $\left(t_{\mathrm{r}}=19.44 \mathrm{~min}\right)$; (9) 2,4,6-trichlorophenol $\left(t_{\mathrm{r}}=22.48 \mathrm{~min}\right)$.

mesogens. For phenols, more substituent methyl groups would lead to more electron-rich benzene rings and hence to larger $\Delta H$ and $\Delta S$ values (Table 2), so the thermodynamic data increase in the order: phenol, $o$-cresol, 2,4-dimethylphenol and 2,4,6-trimethylphenol. Meanwhile the solute-solvent interaction is stronger for the zinc complex than that for the nickel complex. The results are rational since the structure of SmC (zinc complex) is more flexible than that of SmH (nickel complex).
Table 1

Thermodynamic parameters for the dissolution of analytes in the liquid crystal phases of DDTBA-Ni and DDTBA-Zn

\begin{tabular}{|c|c|c|c|}
\hline $\begin{array}{l}\text { Stationary } \\
\text { phase }\end{array}$ & Analyte & $\begin{array}{l}-\Delta H \\
\left(\mathrm{~kJ} \mathrm{~mol}^{-1}\right)\end{array}$ & $\begin{array}{l}-\Delta S \\
\left(\mathrm{~J} \mathrm{~mol}^{-1} \mathrm{~K}^{-1}\right)\end{array}$ \\
\hline \multirow[t]{8}{*}{ DDTBA-Ni } & Phenol & 2.49 & 4.45 \\
\hline & $o$-Cresol & 2.52 & 4.71 \\
\hline & $p$-Cresol & 2.55 & 4.98 \\
\hline & 2,4-Dimethylphenol & 2.58 & 5.14 \\
\hline & 2,4,6-Trimethylphenol & 2.61 & 5.43 \\
\hline & Naphthalene $^{\mathrm{a}}$ & 1.75 & 3.08 \\
\hline & 2-Methylnaphthalene ${ }^{\mathrm{a}}$ & 1.94 & 3.29 \\
\hline & 1-Methylnaphthalene $\mathrm{a}^{\mathrm{a}}$ & 1.96 & 3.28 \\
\hline \multirow[t]{8}{*}{ DDTBA-Zn } & Phenol & 2.57 & 4.64 \\
\hline & $o$-Cresol & 2.63 & 4.98 \\
\hline & $p$-Cresol & 2.63 & 5.19 \\
\hline & 2,4-Dimethylphenol & 2.76 & 5.59 \\
\hline & 2,4,6-Trimethylphenol & 2.82 & 5.95 \\
\hline & Naphthalene $^{\mathrm{a}}$ & 2.21 & 3.99 \\
\hline & 2-Methylnaphthalene ${ }^{a}$ & 2.40 & 4.32 \\
\hline & 1-Methylnaphthalene $\mathrm{a}^{\mathrm{a}}$ & 2.42 & 4.30 \\
\hline
\end{tabular}

${ }^{\mathrm{a}}$ Data from [8].

\subsubsection{Capillary column}

The results shown above indicate that the thermal stability of the nickel complex is better than that of the zinc complex, hence the optimum condition for the separation of phenols with the capillary column was investigated only with the nickel complex. Fig. 6(A) shows a typical chromatogram using the metallomesogenic siloxane polymer capillary column under $115^{\circ} \mathrm{C}$. $m$-Cresol is coeluted with $p$-cresol, and the same situation applies for 2,4,6-trimethylphenol and 2,4-dichlorophenol. Ammonia in nitrogen was used instead of nitrogen as carrier gas. Significant variations in retention time, detector response and peak shape were observed (Fig. 6(B)). Meanwhile, improved selectivity was obtained and more phenols, including 4-bromophenol, 3-methyl-4-chlorophenol and 2,4,6-trichlorophenol, could be separated within a reasonable time. The phenomena indicated that there might be a competitive reaction occurring between phenols and ammonia with the stationary phase. For investigating the column efficiency, isothermal conditions from $100^{\circ} \mathrm{C}$ to $130^{\circ} \mathrm{C}$ were studied (Fig. 7). The elution orders are: 2-chlorophenol<phenol< $o$-cresol=2-nitrophenol $<m$-cresol $<p$-cresol $<2,4,6$-trimethylphenol<2,4-dichlorophenol. Most of them follow the boiling points of these substances, except 2nitrophenol and the pairs $m$-cresol $/ p$-cresol and 2,4- 


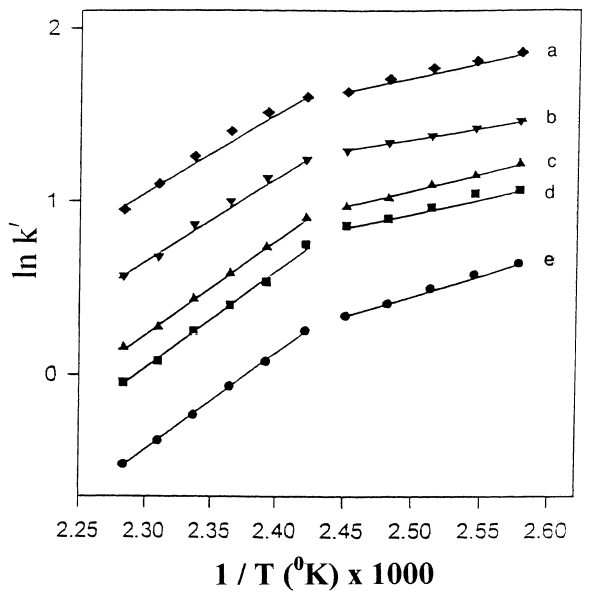

Fig. 4. Van't Hoff plot for phenols. Stationary phase: 5\% DDTBA$\mathrm{Ni}$ coated on Chromosorb; $2.1 \mathrm{~m} \times 3.2 \mathrm{~mm}$ i.d. glass column; mobile phase: nitrogen gas, flow rate: $40 \mathrm{ml} \mathrm{min}^{-1}$; injector temp.: $230^{\circ}$ C. Sample: (a) phenol; (b) $o$-cresol; (c) p-cresol; (d) 2,4dimethylphenol; (e) 2,4,6-trimethylphenol.).

dimethylphenol/2,4,6-trimethylphenol/2,4-dichlorophenol. It was also found that 4-bromophenol, 3methyl-4-chlorophenol and 2,4,6-trichlorophenol strongly adsorbed on the column and no peak was detected during the tested times at $100^{\circ} \mathrm{C}$. Increasing the column temperature decreases the retention time significantly, but the lower boiling point substances are non-resolved.

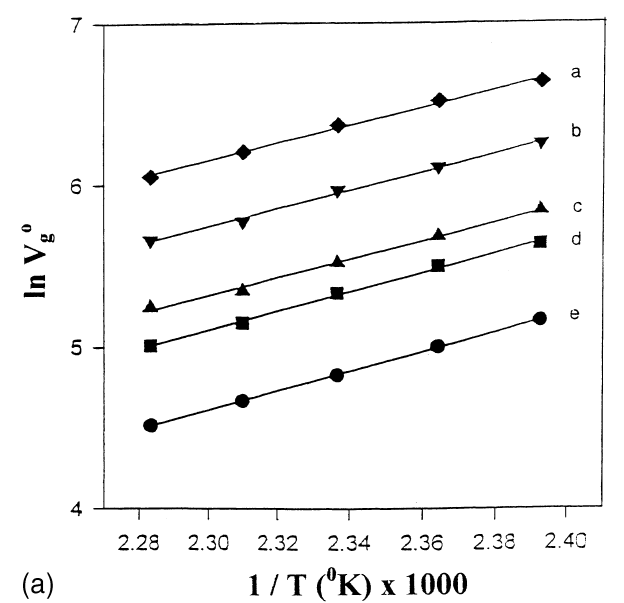

A program with an initial temperature of $100^{\circ} \mathrm{C}$ for $10 \mathrm{~min}$ followed by a $3^{\circ} \mathrm{C} \mathrm{min}{ }^{-1}$ gradient to $170^{\circ} \mathrm{C}$ final temperature was found to produce more satisfactory resolution of phenols. At the same condition but altering the initial temperature only, an even better resolution for $o$-cresol and 2-nitrophenol was found and more phenols could be separated within $30 \mathrm{~min}$ (Fig. 8(A)-(C)), but the pairs $m$-cresol/ $p$-cresol and 3methyl-4-chlorophenol/2,4,6-trichlorophenol were coeluted. Increasing the holding time of the initial temperature, 3-methyl-4-chlorophenol and 2,4,6-trichlorophenol were well resolved but not at the baseline (Fig. 8(D)). The elution orders are 2chlorophenol $<$ phenol $<o$-cresol $<2$-nitrophenol $<m$-cresol $<p$-cresol $<2,4$-dimethylphenol $<2,4,6$-trimethylphenol $<2$,4-dichlorophenol<4-bromophenol $<3$-methyl-4-chlorophenol<2,4,6-trichlorophenol.

\subsection{Separation mechanism}

\subsubsection{Packed column}

The elution mainly follows the order of boiling points of the tested substances. Deviations from the elution order were observed only for the pair 2-chlorophenol/phenol (Fig. 2). Phenols are expected to form complexes with the central metal ion of the metallomesogens coated on Chromosorb. Any change in the substituent of phenols had pronounced effects on the retention time. Chlorine is an electron-donating atom,

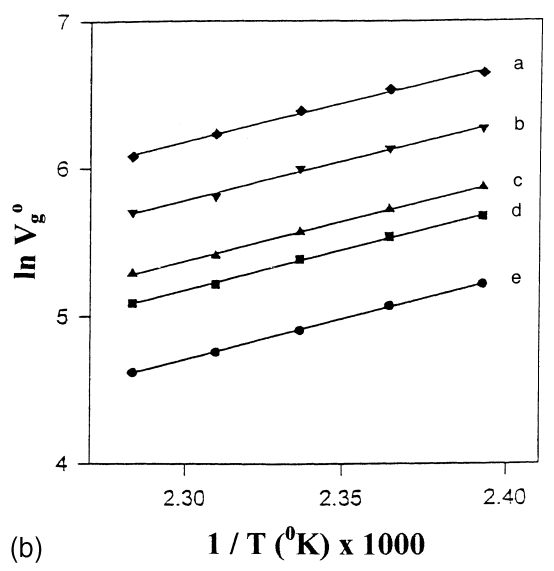

Fig. 5. Temperature dependence of specific retention volume for phenols: (A) stationary phase: 5\% DDTBA-Ni coated on Chromosorb;

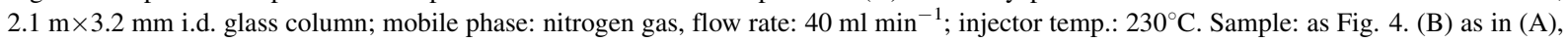
except stationary phase: $5 \%$ DDTBA-Zn coated on Chromosorb. 
Table 2

Optimum conditions for the separation of phenols

\begin{tabular}{|c|c|c|}
\hline & Packed column & Capillary column \\
\hline Stationary phase & $5 \%$ DDTBA-Ni on Chromosorb & DDTBA-Ni siloxane polymer \\
\hline Dimension of column & $2.1 \mathrm{~m} \times 3.2 \mathrm{~mm}$ i.d. glass column & $12 \mathrm{~m} \times 0.25 \mathrm{~mm}$ i.d. fused silica \\
\hline Injector temperature & $250^{\circ} \mathrm{C}$ & $260^{\circ} \mathrm{C}$ \\
\hline Column temperature & $140^{\circ} \mathrm{C}(3 \mathrm{~min})$ to $165^{\circ} \mathrm{C}$ at $3^{\circ} \mathrm{C} \mathrm{min}^{-1}$ & $110^{\circ} \mathrm{C}(15 \mathrm{~min})$ to $170^{\circ} \mathrm{C}$ at $3^{\circ} \mathrm{C} \mathrm{min}^{-1}$ \\
\hline Carrier gas & Nitrogen & $10 \%$ ammonia in nitrogen $(\mathrm{v} / \mathrm{v})$ \\
\hline Flow rate of carrier gas & $40 \mathrm{ml} \mathrm{min}^{-1}$ & $\begin{array}{l}30 \mathrm{ml} \mathrm{min} \operatorname{mit}^{-1} \text { (total flow rate) with split ratio of } \\
1 / 25 ; 40 \mathrm{ml} \mathrm{min}-1 \text { (make-up gas) }\end{array}$ \\
\hline Total weight of Chromosorb & $7.248 \mathrm{~g}$ & \\
\hline Total weight of DDTBA-Ni & $0.382 \mathrm{~g}$ & \\
\hline Molecular weight of DDTBA-Ni & 678.9 & \\
\hline
\end{tabular}

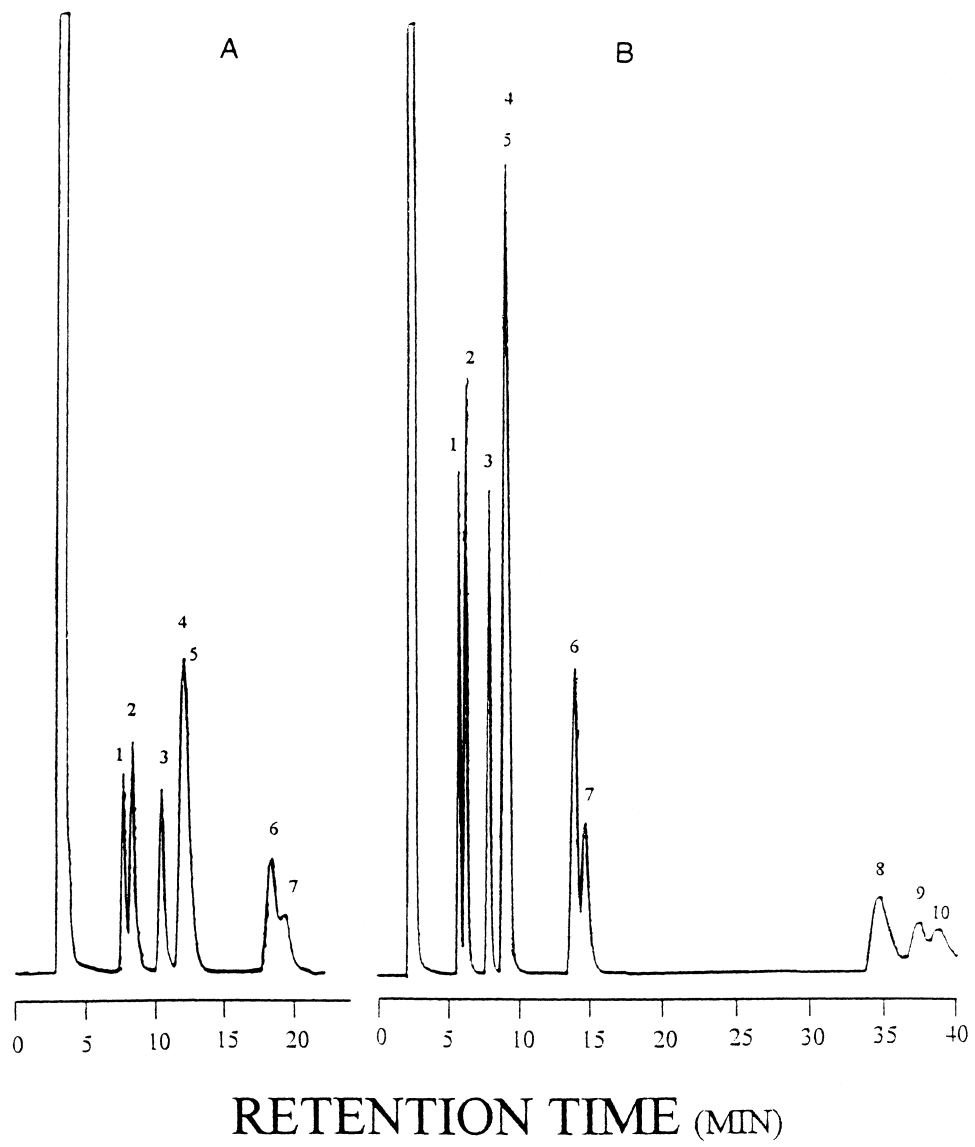

Fig. 6. The separation of phenols using various carrier gases with capillary column. Stationary phase: fused-silica capillary column $\left(12 \mathrm{~m} \times 0.25 \mathrm{~mm}\right.$ i.d.) coated with metallomesogenic siloxane polymer; injector temp.: $260^{\circ} \mathrm{C}$; oven temperature: $115^{\circ} \mathrm{C}$; total flow rate: $30 \mathrm{ml} \mathrm{min}{ }^{-1}$; split ratio: $1 / 30$; make-up gas flow rate: $40 \mathrm{ml} \mathrm{min}{ }^{-1}$. Carrier gas: (A) nitrogen gas; (B) $10 \%$ ammonia in nitrogen (v/v). Peak identification: (1) 2-chlorophenol; (2) phenol; (3) o-cresol; (4) $m$-cresol; (5) p-cresol; (6) 2,4,6-trimethylphenol; (7) 2,4-dichlorophenol; (8) 4bromophenol; (9) 3-methyl-4-chlorophenol; (10) 2,4,6-trichlorophenol. 


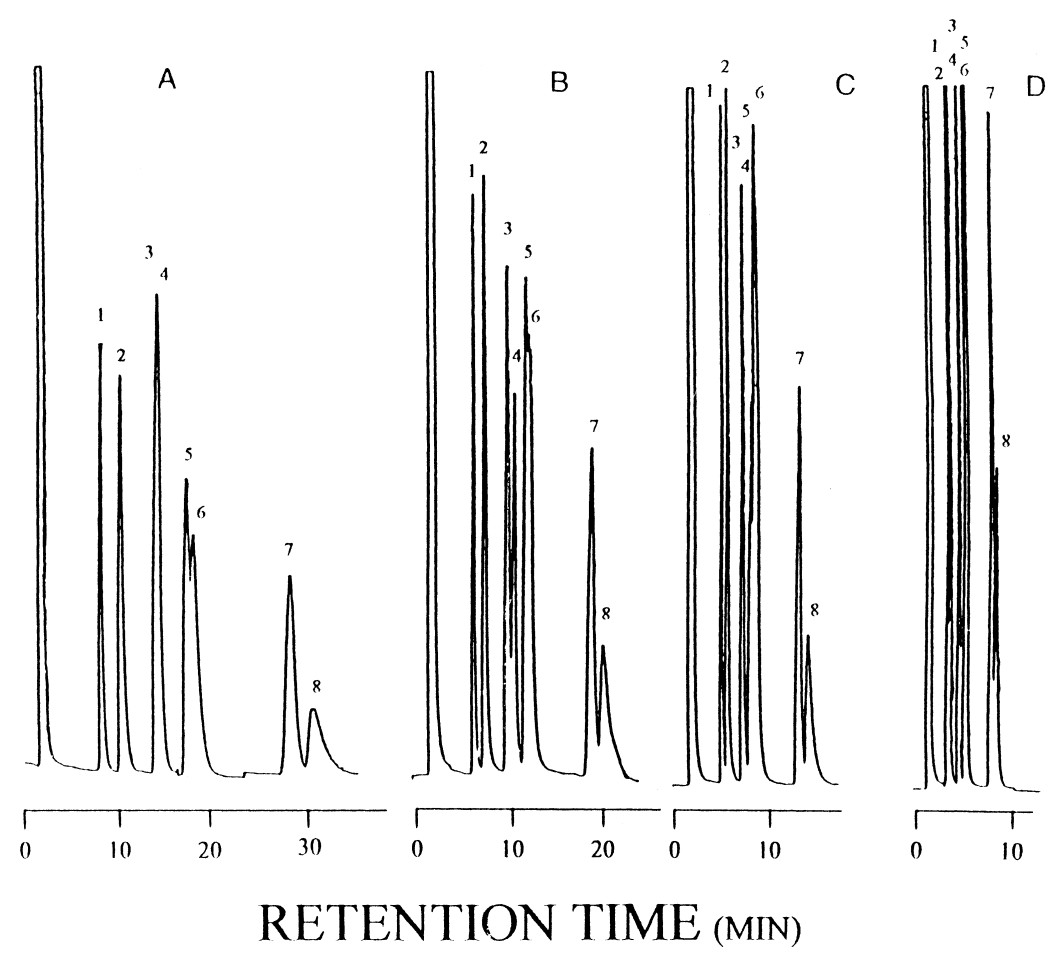

Fig. 7. Separation of phenols at various oven temperatures. Stationary phase: fused-silica capillary column $(12 \mathrm{~m} \times 0.25 \mathrm{~mm}$ i.d. $)$ coated with metallomesogenic siloxane polymer; injector temp.: $260^{\circ} \mathrm{C}$; total flow rate: $30 \mathrm{ml} \mathrm{min}^{-1}$; split ratio: 1/25; make-up gas flow rate: $40 \mathrm{ml} \mathrm{min}{ }^{-1}$. Carrier gas: $10 \%$ ammonia in nitrogen (v/v). Oven temperature: (A) $100^{\circ} \mathrm{C}$; (B) $110^{\circ} \mathrm{C}$; (C) $120^{\circ} \mathrm{C}$; (D) $130^{\circ} \mathrm{C}$. Peak identification: (1) 2-chlorophenol; (2) phenol; (3) $o$-cresol; (4) 2-nitrophenol; (5) $m$-cresol; (6) p-cresol; (7) 2,4,6-trimethylphenol; (8) 2,4dichlorophenol.

2-chlorophenol forms a stronger complex than phenol itself, thus phenol is eluted first. Methyl is an electron releasing group, the effect of the substituent is much greater in the case of $p$-isomer than in the cases of $m$ isomers. Hence the elution order of the positional isomers was $m-<p-$. The greater retention could be explained also by the larger $L / B$ value of the $p$-isomer. 2,4-Dimethylphenol and 2,4-dichlorophenol are similar in b.p. and $L / B$ ratio. Due to the greater MW and a higher affinity toward the central metal ion, 2,4dimethylphenol is eluted as expected followed by 2,4-dichlorophenol, and they are well resolved. 3Methyl-4-chlorophenol and 4-bromophenol were separated successively, and the most retained solute is 2,4,6-trichlorophenol. It can be concluded that the retention behavior seems related mostly to the affinity of metal-ligand interaction. Structural selectivity involving the $L / B$ ratio seems to be only a minor contribution. In other words, the electron density in the donor group favoring the ligand-exchange reaction would explain the unexpected behavior.

\subsubsection{Capillary column}

The favorable chromatographic behavior of the column as demonstrated above might be attributed to multiple properties derived from its chemical structure, i.e., polysiloxane backbone and mesogenic side chains, as well as ligand-exchange reaction. Deviations from the elution order according to boiling points can be observed for 2-nitrophenol and for the pairs $m$ cresol/p-cresol, 2,4-dimethylphenol/2,4,6-trimethylphenol/2,4-dichlorophenol and 4-bromophenol/3methyl-4-chlorophenol. The sequence of most phenols in Fig. 8 agrees very well with that on the packed column which is mainly based on the mechanism of LEGC, except the pairs 2-chlorophenol/phenol and 4bromophenol/3-methyl-4-chlorophenol, which are eluted in reverse order. This might be due to the 

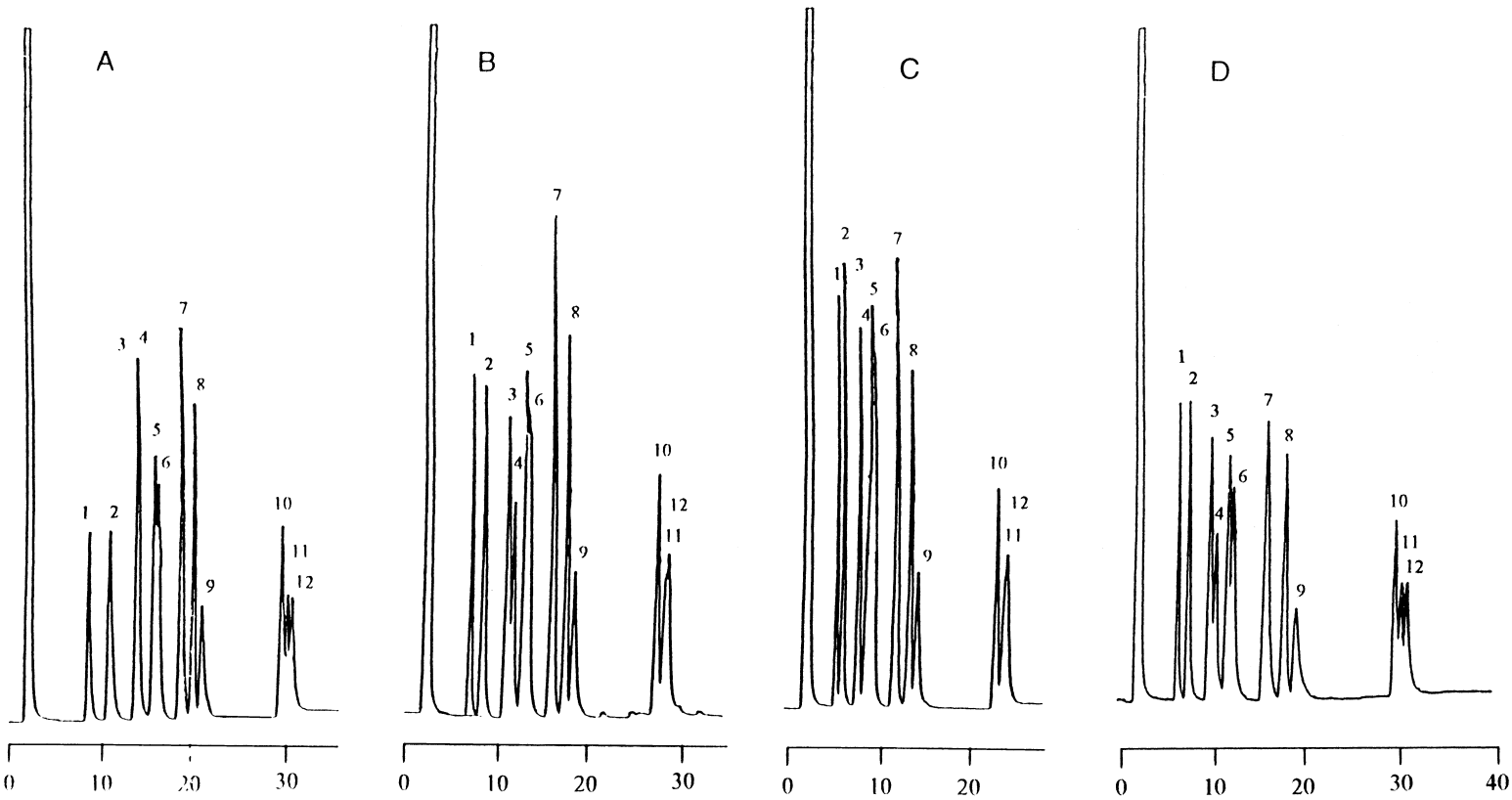

\section{RETENTION TIME (MIN)}

Fig. 8. Separation of phenols under temperature programed conditions. Stationary phase: fused-silica capillary column $(12 \mathrm{~m} \times 0.25 \mathrm{~mm}$ i.d. $)$ coated with metallomesogenic siloxane polymer; injector temp.: $260^{\circ} \mathrm{C}$; carrier gas: $10 \%$ ammonia in nitrogen (v/v); total flow rate: $30 \mathrm{ml} \mathrm{min}^{-1}$; split ratio: $1 / 25$; make-up gas flow rate: $40 \mathrm{ml} \mathrm{min}^{-1}$. Oven temperature: (A) $100^{\circ} \mathrm{C}(10 \mathrm{~min})$ to $170^{\circ} \mathrm{C}$ at $3^{\circ} \mathrm{C} \mathrm{min}{ }^{-1}$; (B) $110^{\circ} \mathrm{C}$ (10 min) to $170^{\circ} \mathrm{C}$ at $3^{\circ} \mathrm{C} \mathrm{min}^{-1}$; (C) $120^{\circ} \mathrm{C}(10 \mathrm{~min})$ to $170^{\circ} \mathrm{C}$ at $3^{\circ} \mathrm{C} \mathrm{min}^{-1}$; (D) $110^{\circ} \mathrm{C}(15 \mathrm{~min})$ to $170^{\circ} \mathrm{C}$ at $3^{\circ} \mathrm{C}$ min ${ }^{-1}$. Peak identification: (1) 2-chlorophenol ( $\left.t_{\mathrm{r}}=6.52 \mathrm{~min}\right)$; (2) phenol ( $\left.t_{\mathrm{r}}=7.68 \mathrm{~min}\right)$; (3) $o$-cresol ( $\left.t_{\mathrm{r}}=10.04 \mathrm{~min}\right)$; (4) 2-nitrophenol $\left(t_{\mathrm{r}}=10.67 \mathrm{~min}\right)$; (5) $\mathrm{m}$-cresol $\left(t_{\mathrm{r}}=11.92 \mathrm{~min}\right)$; (6) $p$-cresol $\left(t_{\mathrm{r}}=12.56 \mathrm{~min}\right)$; (7) 2,4-dimethylphenol $\left(t_{\mathrm{r}}=15.94 \mathrm{~min}\right)$; (8) 2,4,6-trimethylphenol $\left(t_{\mathrm{r}}=17.92 \mathrm{~min}\right)$; (9) 2,4dichlorophenol ( $\left.t_{\mathrm{r}}=19.13 \mathrm{~min}\right)$; (10) 4-bromophenol $\left(t_{\mathrm{r}}=29.35 \mathrm{~min}\right)$; (11) 3-methyl-4-chlorophenol $\left(t_{\mathrm{r}}=30.02\right.$ min); (12) 2,4,6-trichlorophenol $\left(t_{\mathrm{r}}=30.07 \mathrm{~min}\right)$.

greater hydrophobic interaction of phenol and 3methyl-4-chlorophenol with the polysiloxane backbone.

In a ligand-exchange separation mechanism, silica gel bonded with 8-quinolinol and loaded with $\mathrm{Fe}(\mathrm{III})$ was tested by Shahwan and Jezorek [15]. They found that the presence of electron-withdrawing substituents in the ortho- and para-positions of the phenol results in substantially increased retention relative to phenol itself. These substituents decrease the electron density in the aromatic ring, and hence the $\pi-\pi$ interactions. However, they also decrease the electron density on the phenolic oxygen permitting stronger hydrogen bonding by the phenolic proton. The substantially greater retention exhibited by these compounds suggests that hydrogen bonding is a major interaction with the stationary phase. The presence of the methyl group results in greater electron density on the aromatic ring and hence $\pi-\pi$ interactions, as well as dispersion interactions, are enhanced. In their work, the substituents $\mathrm{Cl}, \mathrm{CH}_{3}$ and $\mathrm{NO}_{2}$ increased retention compared with phenol. The same phenomena were indicated in our study, although their work was in the liquid system.

\subsection{Linear calibration range}

The optimum conditions for the separation of phenols are summarized in Table 2. Solution mixtures containing known amounts of phenols were prepared and used for the construction of calibration graphs. Under optimum conditions, the calibration graphs of peak height against the quantity of each analyte were found to be linear over the concentration range stu- 
Table 3

Calibration equations for the determination of phenols

\begin{tabular}{|c|c|c|c|c|}
\hline Compound & Regression equation $^{\mathrm{b}}$ & Correlation coefficient $^{\mathrm{b}}$ & Linear range $\left(\mu \mathrm{g} \mathrm{ml}^{-1}\right)$ & Detection limit (ng) \\
\hline \multicolumn{5}{|l|}{ With packed column ${ }^{\mathrm{a}}$} \\
\hline Phenol & $y=27.1 x-105.6$ & 0.9998 & $64-1600$ & 22 \\
\hline 2-Chlorophenol & $y=27.4 x-168.7$ & 0.9997 & $64-1600$ & 22 \\
\hline$o$-Cresol & $y=25.4 x-147.2$ & 0.9998 & $64-1600$ & 22 \\
\hline p-Cresol & $y=24.6 x-60.2$ & 0.9997 & $64-1600$ & 24 \\
\hline 2,4-Dichlorophenol & $y=23.3 x-121.4$ & 0.9989 & $64-1600$ & 24 \\
\hline 3-Methyl-4-chlorophenol & $y=20.2 x-107.6$ & 0.9975 & $64-1600$ & 32 \\
\hline 4-Bromophenol & $y=19.9 x-257.0$ & 0.9972 & $64-1600$ & 32 \\
\hline 2,4,6-Trichlorophenol & $y=19.3 x-103.1$ & 0.9974 & $64-1600$ & 32 \\
\hline \multicolumn{5}{|l|}{ With capillary column ${ }^{\mathrm{c}}$} \\
\hline 2-Chlorophenol & $y=109.9 x-167.3$ & 0.9974 & $16-400$ & 4 \\
\hline Phenol & $y=109.9 x-171.3$ & 0.9983 & $16-400$ & 4 \\
\hline$o$-Cresol & $y=101.5 x-73.4$ & 0.9985 & $16-400$ & 4 \\
\hline 2-Nitrophenol & $y=87 x-143.2$ & 0.9985 & $16-400$ & 4 \\
\hline$p$-Cresol & $y=92.0 x-147.4$ & 0.9948 & $16-400$ & 4 \\
\hline 2,4-Dimethylphenol & $y=90.7 x-104.7$ & 0.9954 & $16-400$ & 4 \\
\hline 2,4,6-Trimethylphenol & $y=59.8 x-116.6$ & 0.9941 & $16-400$ & 7 \\
\hline 2,4-Dichlorophenol & $y=82.6 x-84.2$ & 0.9956 & $16-400$ & 5 \\
\hline 3-Methyl-4-chlorophenol & $y=41.8 x-126.3$ & 0.9922 & $16-400$ & 10 \\
\hline 4-Bromophenol & $y=46.8 x-99.4$ & 0.9921 & $16-400$ & 10 \\
\hline 2,4,6-Trichlorophenol & $y=37.6 x-101.2$ & 0.9918 & $16-400$ & 10 \\
\hline
\end{tabular}

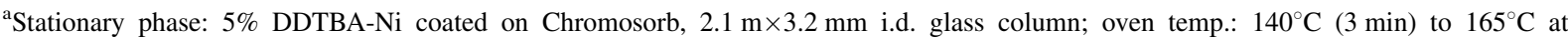
$3^{\circ} \mathrm{C} \mathrm{min}{ }^{-1}$; injection temp.: $250^{\circ} \mathrm{C}$; mobile phase: nitrogen gas, flow rate: $40 \mathrm{ml} \mathrm{min}^{-1}$.

$\mathrm{b} y=$ Peak height, $x=$ phenol conc. $\left(\mu \mathrm{g} \mathrm{ml}^{-1}\right)$, number of measurements: 8 .

${ }^{\mathrm{c}}$ Stationary phase: fused-silica capillary column $(12 \mathrm{~m} \times 0.25 \mathrm{~mm}$ i.d.) coated with metallomesogenic siloxane polymer; injector volume: $1 \mu \mathrm{l}$; injector temp.: $260^{\circ} \mathrm{C}$; oven temperature: $110^{\circ} \mathrm{C}(15 \mathrm{~min})$ to $170^{\circ} \mathrm{C}$ at $3^{\circ} \mathrm{C} \mathrm{min}^{-1}$; carrier gas: $10 \%$ ammonia in nitrogen $(\mathrm{v} / \mathrm{v})$; total flow rate: $30 \mathrm{ml} \mathrm{min}^{-1}$; split ratio: $1 / 25$; make-up gas flow rate: $40 \mathrm{ml} \mathrm{min}^{-1}$.

died, i.e., 64-1600 $\mu \mathrm{g} \mathrm{ml}^{-1}$ (packed column) and 16$400 \mu \mathrm{g} \mathrm{ml}^{-1}$ (capillary column) for an injection volume of $1 \mu \mathrm{l}$. The results were summarized in Table 3(A) and (B). The mass detection limits of most phenols, defined as the minimum weight of analyte that can be detected at a known confidence level (95\%, i.e., $2 \sigma$ ) [21], are less than $30 \mathrm{ng}$ (packed column) and $4 \mathrm{ng}$ (capillary column).

\section{Conclusion}

Nowadays, the most widely used analytical technique for the determination of phenols is gas chromatography. However, phenols tend to produce broad peaks (often with tailing) due to their high polarity and low vapor pressure, which increase with aging of the column. Derivatization of phenols prior to analysis is necessary to give less polar compounds with better chromatographic characteristics [22]. In this study, both nickel and zinc complexes of $p$-decanoxydi thiobenzoate could be used as gas chromatography stationary phases for the separation of phenols. However, a slightly different selectivity could be seen for the separation of higher boiling point phenols. The phenomena indicate that nickel complex is superior to the zinc complex. The nickel complex either coated on Chromosorb or its siloxane polymer coated on a capillary column are efficient for the separation of phenols. The procedures are direct and efficient, and derivatization is not necessary. Nitrogen gas can be used as carrier gas, but ammonia in nitrogen improves the peak shape and selectivity. The prepared columns are highly promising for the separation and determination of phenols in environmental samples. 


\section{Acknowledgements}

We thank the National Science Council of the Republic of China (Taiwan) for financial support.

\section{References}

[1] R.A. Weiss, C.K. Ober (Eds.), Liquid-Crystalline Polymers, American Chemical Society, Washington, DC, 1990.

[2] Z. Witkiewicz, J. Chromatogr. 466 (1989) 37.

[3] L. Oriol, J.L. Serrano, Adv. Mater. 7 (1995) 348.

[4] K. Fujimura, M. Kitanaka, H. Takayanagi, T. Ando, Anal. Chem. 54 (1982) 918.

[5] H. Takayanagi, M. Hashizume, K. Fujimura, T. Ando, J. Chromatogr. 350 (1985) 63.

[6] H. Takayanagi, M. Akita, K. Fujimura, T. Ando, J. Chromatogr. 350 (1985) 75.

[7] P. Berdague, F. Perez, J. Courtieu, J.P. Bayle, O. Abdelhadi, S. Guermouche, M.H. Guermouche, J. High Resolut. Chromatogr. 18 (1995) 304.

[8] C.C. Hu, C.Y. Liu, Anal. Chim. Acta 332 (1996) 23.
[9] C.Y. Liu, C.C. Hu, C.L. Yang, J. Chromatogr. A 773 (1997) 199.

[10] V.A. Davankov, J.D. Navratil, H.F. Walton, Ligand Exchange Chromatography, CRC Press, Boca Raton, FL, 1988.

[11] D. Cagniant (Ed.), Complexation Chromatography, Marcel Dekker, New York, 1992.

[12] P. Mubmann, K. Levsen, W. Radeck, Fresenius' J. Anal. Chem. 348 (1994) 654.

[13] B.M. Petronio, A. Lagana, M.V. Russo, Talanta 28 (1981) 215.

[14] B.M. Petronio, A. Lagana, G.D. Andrea, Talanta 31 (1984) 357.

[15] G.J. Shahwan, J.R. Jezorek, J. Chromatogr. 256 (1983) 39.

[16] K. Grob, G. Grob, J. High Resolut. Chromatogr. Chromatogr. Commun. 5 (1982) 119.

[17] J. Rayss, Z. Witkiewicz, A. Waksmundzki, R. Dabrowski, J. Chromatogr. 188 (1980) 107

[18] S. Ghodbane, G.A. Oweimreen, D.E. Martire, J. Chromatogr. 556 (1991) 317.

[19] E.F. Meyer, J. Chem. Educ. 50 (1973) 191.

[20] G.M. Janini, M.T. Ubeid, J. Chromatogr. 236 (1982) 329.

[21] D.A. Skoog, F.J. Holler, T.A. Nieman, Principles of Instrumental Analysis, 5th ed., Saunders, Philadelphia, 1998, p. 13.

[22] D. Puig, D. Barcelo, Trends Anal. Chem. 15 (1996) 362. 